\title{
ANALYSIS OF CORRELATION BETWEEN THE STATE OF GROUNDWATER AND THE STATE OF TERRESTRIAL ECOSYSTEMS INCLUDING WETLANDS
}

\author{
Mihaela Scradeanu ${ }^{1}$, Virgil lordache ${ }^{2}$, Marin Palcu ${ }^{3}$, Daniel Scradeanu ${ }^{1}$
}

'University of Bucharest, Faculty of Geology and Geophysics, 6 Traian Vuia Str., Section 2, Bucharest, Romania.

2University of Bucharest, Faculty of Biology, 91-95 Splaiul independentei, Section 5, Bucharest, Romania.

${ }^{3}$ Romanian Association of Hydrogeologists, 6 Traian Vuia Str., Section 2, Bucharest, Romania

\begin{abstract}
Analysis of correlation between the state of terrestrial ecosystems and groundwater aims the preservation of natural state of ecosystems in terms of sustainable exploitation of groundwater. The proposed analysis determines the intensity of dependence between ecosystems and groundwater based on two categories of criteria: hydrogeological criteria (HC: lithology of aquifer formations, vadose zone humidity, piezometric level depth and qroundwater quality) and environmental criteria (EC: the number of characteristic organisms, production function, role in cycling elements etc.).

The analysis contains two algorithms: one for identifying the potential ecosystems dependent on groundwater and one for estimating the intensity of interdependence on three levels: high dependence (A: 100\%), medium dependence (B: 50\%) and nule dependence (C: $0 \%$ ).

Validation of the proposed analysis was conducted on a case study in Oltenia. In the selected area, the evaluation of dependence intensity for each Nature 2000 site was made using one criteria that maximizes the dependence and one that minimizes.

The proposed analysis uses GIS techniques and a database supplied with information from public monitoring systems of groundwater, SCls-Nature2000 and habitats, Corine Land Cover databases.
\end{abstract}

Keywords: environmental criteria, groundwater, GIS, hydrogeological criteria, SCI_Nature 2000.

\section{Introduction}

Our analysis of correlation between the state of terrestrial ecosystems and groundwater is generated by the fact that one of the basic principles of groundwater protection policy against pollution and deterioration, included in EU Water Framework Directive 2000/60 EC and Directive 2006/118/EC, is: "If a groundwater resource or quality pressure is causing 'significant damage' to terrestrial ecosystems including wetlands, then the groundwater body will not be in "good status" [1], [2].

The difficulty of defining the correlation between terrestrial ecosystems and groundwater compel a maximum caution which aims to conserve the natural resources and use them in a sustainable manner [3].

The proposed methodology for analysis includes: criteria and algorithm for identification of dependence between ecosystems and groundwater and algorithm for assessing degree of dependence for each habitat and for entire studied area. 
For the case study, conducted in Oltenia region, the main hydrogeological criteria used was the piezometric head of groundwater in correlation with some environmental criteria like: deep root system of plants, the number of characteristic organisms and in addition, the 44 classes/categories of land use (extracted from the Corine Land Cover database).

The result of our analysis is the average level of correlation for each $\mathrm{SCl}$ and habitat from the studied area, separated into three categories: high dependence $(\mathbf{A})$, medium dependence $(\mathbf{B})$ and nule dependence (C) (Table 3).

\section{Materials and Methods (or Experimental)}

Correlation between the state of terrestrial ecosystems and groundwater is made based on a new methodology which has three basic steps:

- $\quad$ identifying criteria for determining the correlation between ecosystems and groundwater

- $\quad$ accurate algorithm for identifying correlations between ecosystems and groundwater

- $\quad$ evaluating the intensity of correlation between ecosystems and groundwater

The criteria used to assess the correlation between ecosystems and groundwater was separated into two categories:

- hydrogeological criteria (HC) like: the recharge area of phreatic aquifer hydrodynamic relationships between groundwater bodies and surface water (lakes, rivers and wetlands) [4]

- ecological criteria (EC) like: the

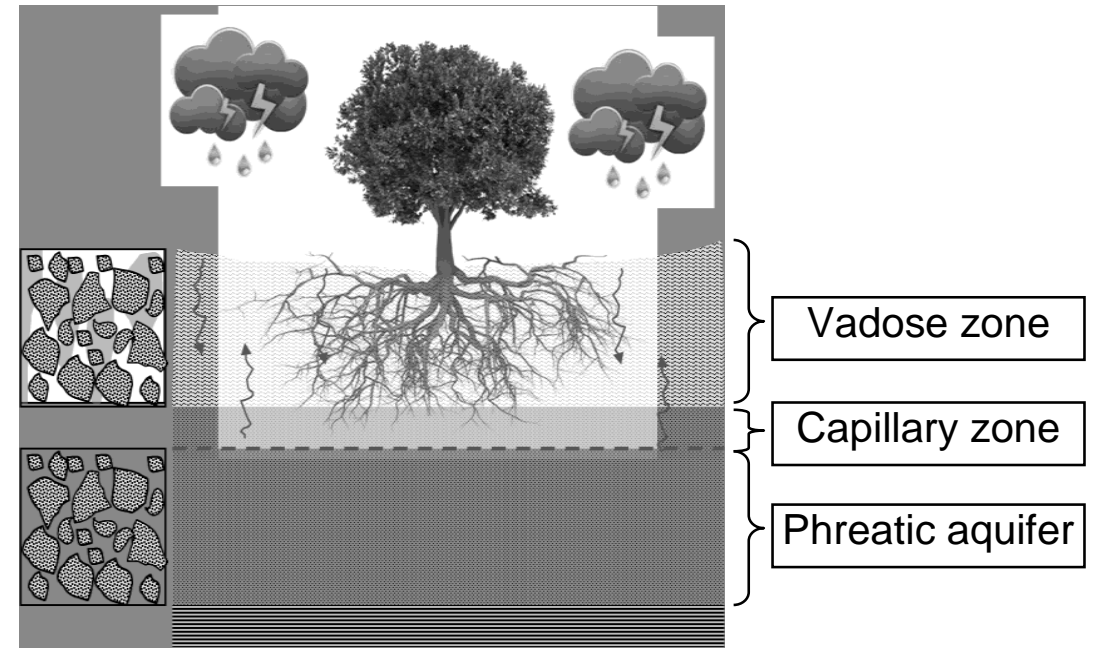

Fig. 1. The recharge area for phreatic aquifer and the access area of groundwater to the root system of plants

number of characteristic organisms, production function, role in cycling elements etc. [3], [5], [6].

The algorithm for identifying correlations between ecosystems and groundwater bodies (Fig. 2) uses a database containing: areas of surface water bodies, areas of groundwater bodies (phreatic and confined), areas of ecosystems and types of hydrodinamic connections between water bodies.

The main steps of the algorithm are:

- $\quad$ mapping of water bodies

- $\quad$ specifying the types of connections between water bodies

- $\quad$ mapping of ecosystems

- $\quad$ intersection of water bodies and ecosystems

- $\quad$ framing the type of relationship between water bodies and ecosystems in two classes: dependent ecosystem and independent ecosystem (using hydrogeologicel criteria $(\boldsymbol{H A})$ and ecological criteria $(\boldsymbol{E C})$ 


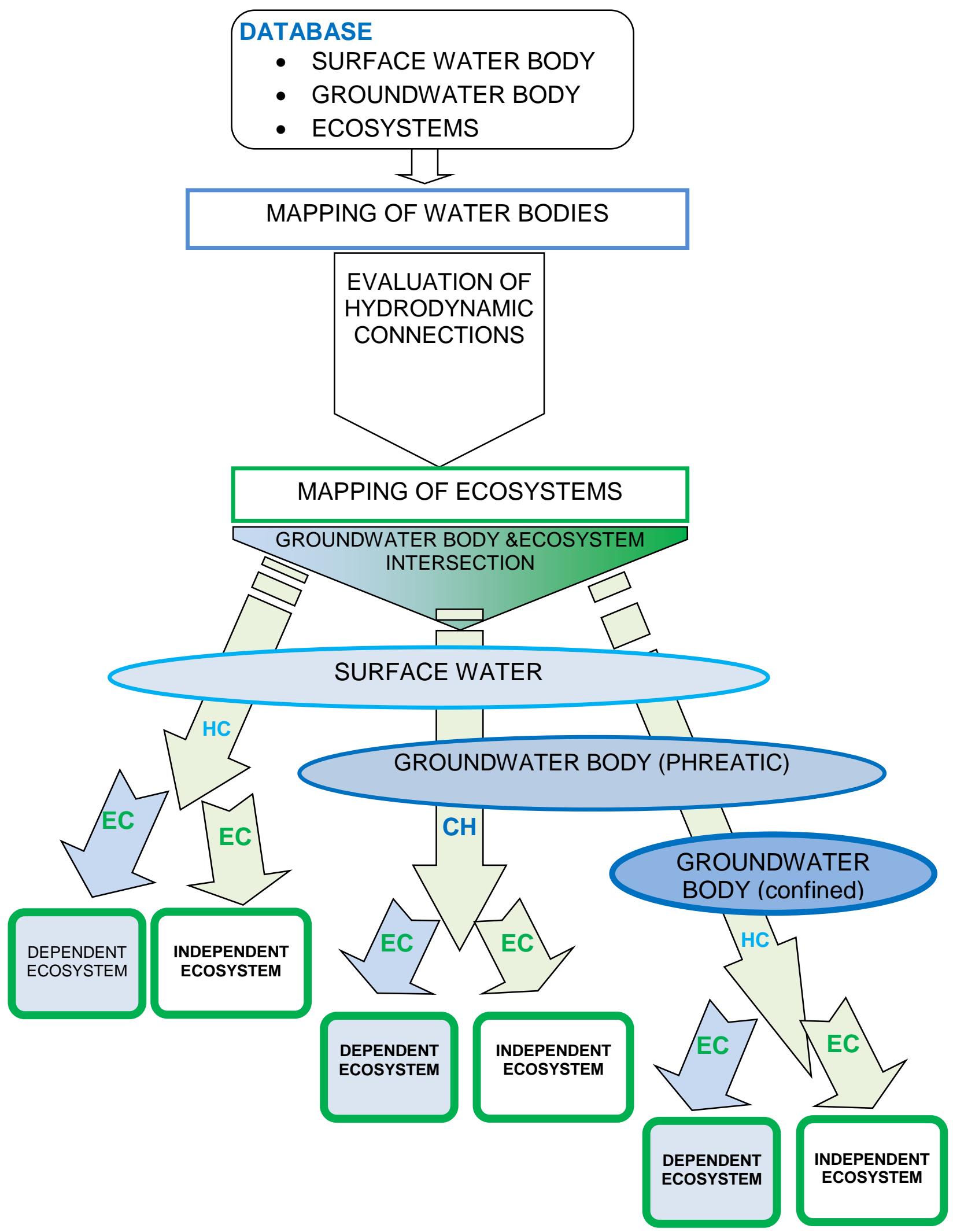

Fig. 2. Algorithm for identifying correlations between ecosystems and groundwater bodies (surface water, groundwater body (phreatic/confined) 
The algorithm for evaluation of the intensity of correlation between ecosystems and groundwater (Fig. 3) applies only to ecosystems dependent on groundwater potential identified in the second stage of the methodology.

Applying the two categories of criteria (hydrogeological criteria: $\mathrm{CH}$ and ecological criteria: EC) leads to two series of assessments for the corresponding dependency. All the criteria may generate, depending on the conditions of the land, three dependency levels:

- $\quad$ high dependence: A: $100 \%$

- medium dependence: $\mathrm{B}: 50 \%$

- nule dependence: C: $0 \%$

It follows that an ecosystem dependent on groundwater potential will have after applying the algorithm, a number of indices (A / B / C) equal to the number of hydrogeological criteria $(\mathrm{HC})$ and ecological criteria $(\mathrm{EC})$. Establishing the degree of dependence for a studied area, with several ecosystems, is proposed to be quantified by two indices [7]:

- $\quad$ maximum dependency index (C1) - equal to the maximum dependency level identified for all ecosystems from studied area.

$$
C 1=M A X\left(D E P_{E_{1}}, D E P_{E_{2}}, \ldots, D E P_{E_{n}}\right)
$$

where

$D E P_{E_{1}}$ - level of dependency for $E_{1}$ ecosystem ( $\mathrm{A}=100 \%, \mathrm{~B}=50 \%$ and $\mathrm{C}=0 \%$ )

$n \quad$ - total number of ecosystems in the studied area.

- $\quad$ medium dependency index (C2) - calculated as a average of dependency levels weight with the surface of each ecosystem identified in the studied area only for level of dependency A or B.

$$
C 2=\frac{\sum_{i=1}^{i-n} D E P_{E_{i}} \cdot S_{E_{i}}}{\sum_{i=1}^{i=n} S_{E_{i}}} \text { with values: }\left\{\begin{array}{lll}
A & \text { if } & C 2 \geq 75 \% \\
B & \text { if } & C 2<75 \%
\end{array}\right.
$$

where

$S_{E_{i}}$ - the area of ecosystem „i"

C2 is not calculated in areas with independent ecosystems (level of dependency is $\mathrm{C}=0 \%$ ).

Acording to the principle of minimum precaution for any area where there is a dependent ecosystem is given a level of dependency B. If C2>75\% the level of dependency is increased to $A$. 


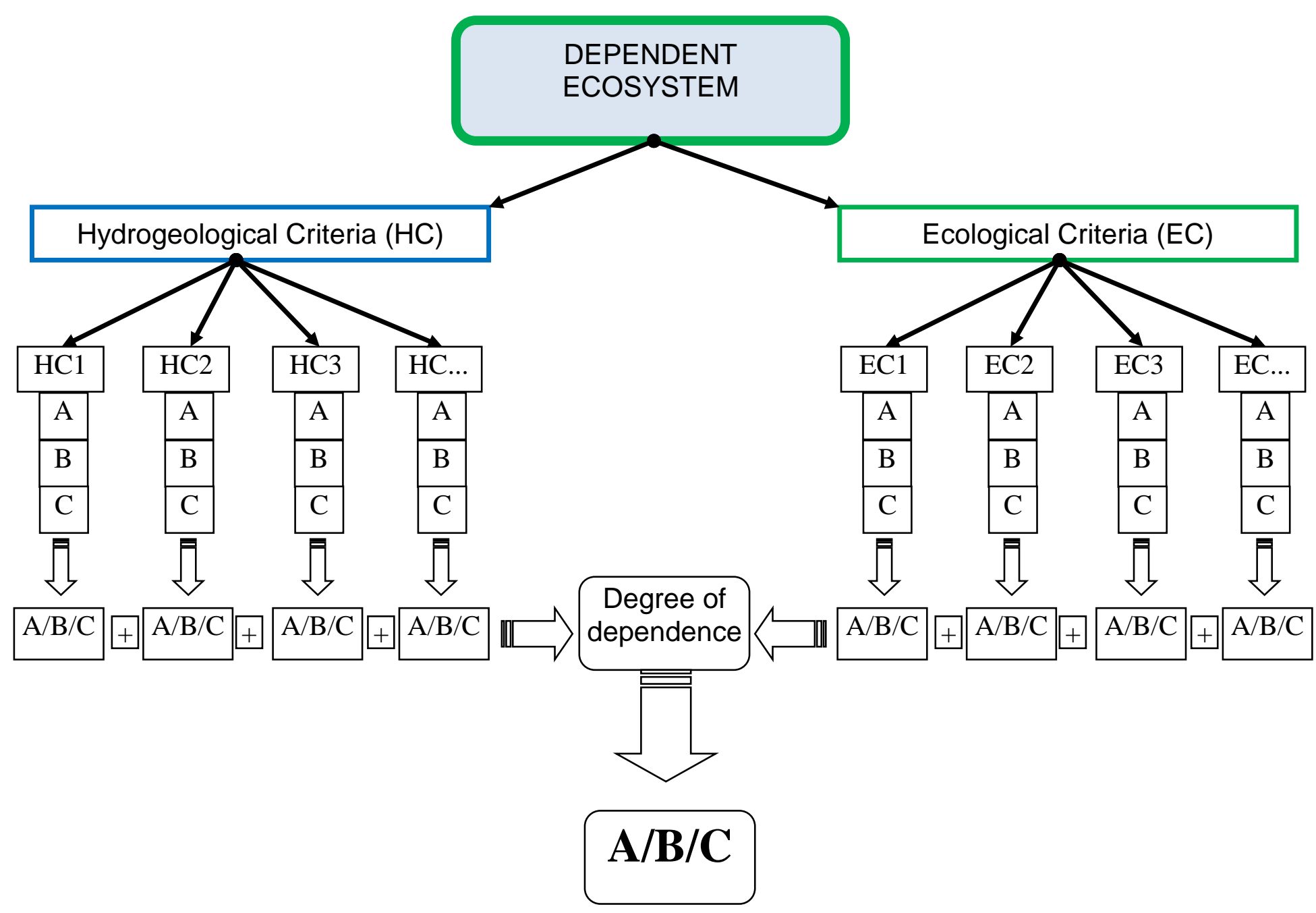

Fig. 3. The algorithm for evaluation of the intensity of correlation between ecosystems and groundwater 


\section{Results and Discussion}

The case study applies the methodology developed for the analysis of correlation between groundwater bodies and terrestrial ecosystems in the Oltenia region placed in southwestern Romania (Fig. 4) with a complex hydrostructure and a wide variety of Nature 2000 sites.

The areas where the dependency between terrestrial ecosystems and groundwater aquifers becomes possible are:

- $\quad$ phreatic aquifers

- $\quad$ natural emergency of aquifers like wetlands and surface waters (lake and rivers) recharged from groundwater.

Database needed to analyse the correlation between ecosystems and groundwater, in the studied area, consists in:

- water bodies of regional hydrostructure Oltenia

[8]:

\section{(Fig. 5a)}

preatic aquifers: ROJI05, ROJI06, ROOT08

- deep aquifers: ROOT13, ROJI07

- ecosystems from the network Nature 2000

(SPA \& SCI) in the same area [9]:

- ROSPA: 0011, 0046, 0013, 0023, 0196, 0024, 0137

- ROSCI: 0039,0202, 0045, 0306, 0173, 0403, 0296, 0299, 0376, 0166, 0168, 0183, 0174, 0011, 0266, 0359, 0362, 0366 (Fig. 5b)

- habitats from nationat network (10x10km) in the studied area:

- 6510, 6120, 91IO, 2190, 92A0, 91M0, 3260, 6440, 9170, 91 Y0 (Fig.5c)

- dependency/depth of piezometric level (Table 1) [10]

- land use categories (Corine Land Cover; [11]):

○ $\quad 311,312,313,321,324$ (Fig. 5d)

○ dependency/depth of piezometric level (Table 2) 

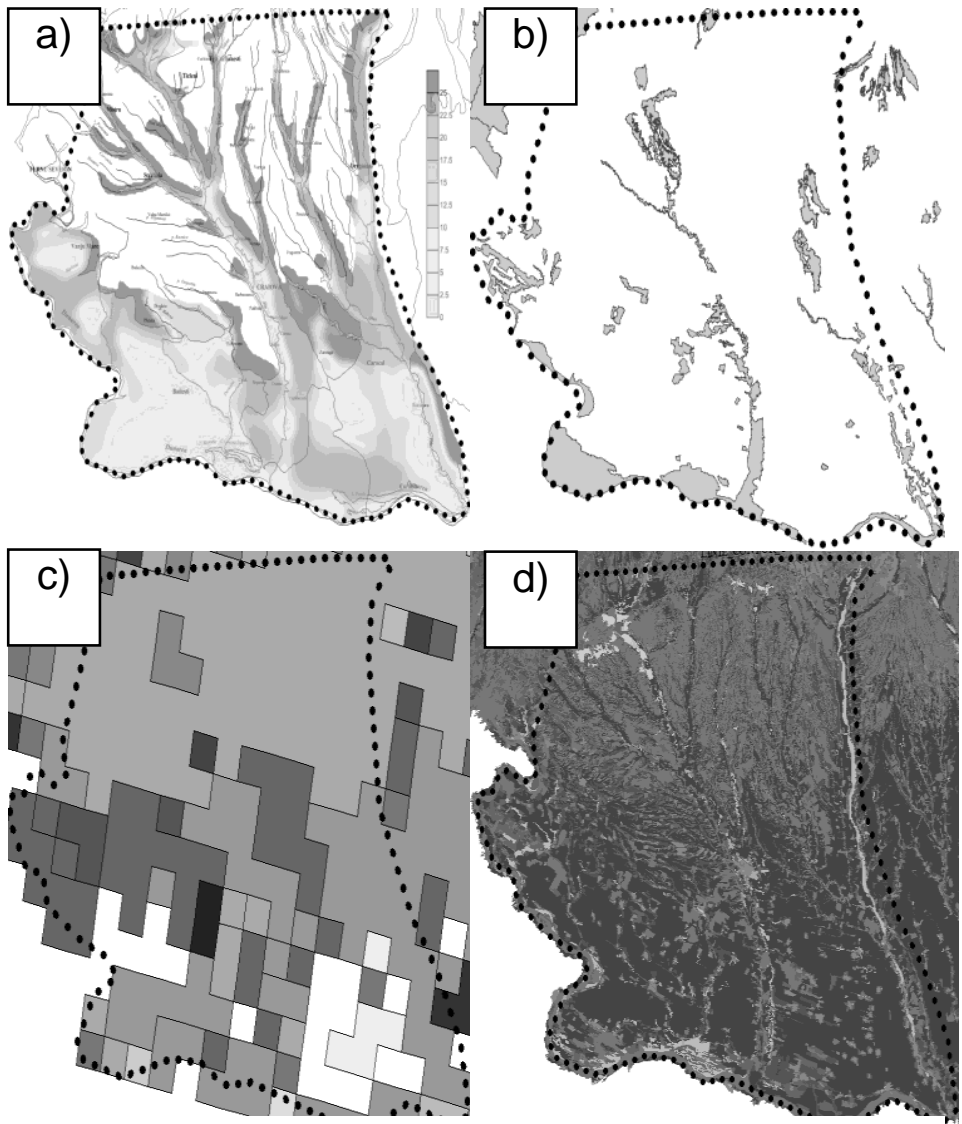

Fig. 5. Database for case study: a) depth of piezometric level; b) the $18 \mathrm{SCl}$; c) habitats $(10 \times 10 \mathrm{~km}) ; d)$ the land use categories.

The results of methodology conducted in Oltenia with both criteria ( $\mathrm{C} 1$ and $\mathrm{C} 2)$ are included in Table 3. It follows that the two criteria ( $\mathrm{C} 1$ and $\mathrm{C} 2$ ) lead to different results only in large areas (Table 4).

The relevance of these results obtained by applying the proposed methodology depends on [12]:

- accuracy spatial delimitation of groundwater bodies, ecosystems and habitats

- representativeness of the data used to assess the depth of piezometric level of groundwater bodies and hydrodynamic relations.

The two recommended criteria for assessing the degree of dependence of ecosystems to groundwater bodies should be selected according to:

- $\quad$ protecting biodiversity without taking any risk of deterioration (criteria C1);

- $\quad$ reducing the number of representative habitat types according to the percentage of the surface in the studied area (criteria C2).

\section{Conclusions}

The proposed methodology allows a satisfactory identification and ranking of ecosystems dependent on groundwater according to the depth of piezometric level of aquifers. 
We appreciate that the correct identification of groundwater dependent ecosystems is possible in special cases where there are studies based on mathematical models of coupled flow of surface water, groundwater and ecological processes.

Such studies are recommended for protecting ecosystems of special importance where they can be affected by irrational exploitation of groundwater bodies.

\section{Acknowledgements}

The authors would like to thank Romanian Waters National Administration which provided general information on groundwater bodies.

\section{References}

[1] Water Framework Directive (2000/60) EChttp://eur-lex.europa.eu/legalcontent/EN/TXT/?uri=celex:32000L0060

[2] Directive (2006/118) EC - http://eurlex.europa.eu/legal-

content/EN/TXT/?uri=CELEX:32006L0118

[3] Hocking M. J., Beverly,C., (2011), Groundwater dependent ecosystem mapping: the role of modeling in defining GDE under varying land use and climate, 19th International Congress on Modeling and Simulation, Perth, Australia

[4] Scradeanu D., Gheorghe A., (2007), General Hydrogeology, University of Bucharest Publishing

[5] Orellana F., Verma P., Loheide S. P., Daly E., (2012), Monitoring and modeling watervegetation interactions in groundwaterdependent ecosystems, Review of Geophysics, 50, RG3003.

[6] UK advisory group on WFD,(2004), Guidance on the identification and risk terrestrial ecosystems - draft, assessment of groundwater dependent

\begin{tabular}{|c|c|c|c|c|}
\hline \multicolumn{5}{|c|}{$\begin{array}{c}\text { Table 4. Areas (S) of SCl and habitats in } \\
\text { studied area }\end{array}$} \\
\hline \multirow[t]{2}{*}{ No } & \multicolumn{2}{|c|}{$\mathrm{SCl}$} & \multicolumn{2}{|c|}{ Habitat } \\
\hline & Code & $\begin{array}{c}\mathrm{S} \\
{[\mathrm{km} 2]}\end{array}$ & Code & $\begin{array}{c}\mathrm{S} \\
{[\mathrm{km} 2]}\end{array}$ \\
\hline 1 & ROSCI0366 & 19.2 & 9170 & 19.2 \\
\hline 2 & ROSCI0362 & 4.4 & 9170 & 4.4 \\
\hline \multirow[t]{5}{*}{3} & \multirow[t]{5}{*}{ ROSCI0045 } & \multirow[t]{5}{*}{714.5} & 6440 & 0.0 \\
\hline & & & 9170 & 200.0 \\
\hline & & & $92 \mathrm{~A} 0$ & 0.0 \\
\hline & & & 6510 & 23.0 \\
\hline & & & 3270 & 20.0 \\
\hline \multirow[t]{5}{*}{4} & \multirow[t]{5}{*}{ ROSCI0039 } & \multirow[t]{5}{*}{398.0} & 6510 & 44.0 \\
\hline & & & 6120 & 79.0 \\
\hline & & & 9110 & 0.0 \\
\hline & & & 2190 & 0.0 \\
\hline & & & $92 \mathrm{~A} 0$ & 77.0 \\
\hline 5 & ROSCI0202 & 31.0 & $91 \mathrm{M} 0$ & 31.0 \\
\hline \multirow{2}{*}{6} & \multirow{2}{*}{ ROSCI0306 } & \multirow[t]{2}{*}{134.0} & $91 \mathrm{M} 0$ & 0.0 \\
\hline & & & 92A0 & 0.0 \\
\hline 7 & ROSCI0173 & 12.0 & $92 \mathrm{~A} 0$ & 5.0 \\
\hline 8 & ROSCI0403 & 7.0 & $91 \mathrm{YO}$ & 7.0 \\
\hline 9 & ROSCI0296 & 7.0 & 9170 & 7.0 \\
\hline 10 & ROSCl0376 & 59.0 & 92A0 & 0.0 \\
\hline \multirow[t]{2}{*}{11} & \multirow[t]{2}{*}{ ROSCI0168 } & \multirow[t]{2}{*}{68.0} & 92A0 & 58.0 \\
\hline & & & 9170 & 15.0 \\
\hline 12 & ROSCI0183 & 4.0 & $92 \mathrm{~A} 0$ & 15.0 \\
\hline 13 & ROSCI0166 & 16.0 & $92 \mathrm{~A} 0$ & 0.0 \\
\hline 14 & ROSCI0174 & 0.7 & 9110 & 4.0 \\
\hline 15 & ROSCI0011 & 3.0 & 9110 & 0.7 \\
\hline 16 & ROSCI0266 & 15.0 & 9110 & 3.0 \\
\hline 17 & ROSCI0359 & 24.0 & $92 \mathrm{~A} 0$ & 0.0 \\
\hline 18 & ROSCI0299 & 46.0 & 9170 & 24.0 \\
\hline
\end{tabular}

http://www.wfduk.org/sites/default/files/Media/Characterisation\%20of\%20the\%20water\%20e nvironment/Risk\%20assessment\%20of\%20terrestrial\%20ecosystems\%20groundwater Draft 210104.pdf.

[7] Scradeanu D., Popa R., (2001), Applied Geostatistics, University of Bucharest Publishing [8] Palcu M., (2002), Regional aquifer modeling behavior of Oltenia Dacian lower drainage conditions for the exploitation of lignite deposits and providing municipalities with water, PhD Thesis, University of Bucharest

[9] Nature 2000 network (assessed 2015): http://natura2000.eea.europa.eu/\# ,

[10] RO-Habitate (2013), http://cdr.eionet.europa.eu/ro/eu/art17/envurmdya/

[11] Corine Land Cover, (2000), http://www.eea.europa.eu/data-and-maps/data/corine-landcover-2000-clc2000-seamless-vector-database . 
[12] European Commission, (2014), Technical Report number 8 on methodologies used for assessing groundwater dependent terrestrial ecosystems, 2014-081; https://circabc.europa.eu/sd/a/1448ec4b-a1e0-4627-856e-

d21e5dbbb4db/Technical report No8 methodologies used assessing GWDTEs.pdf 